\title{
Modeling of Winter Hardiness Formation in Winter Wheat Plants
}

\author{
A.N. Polevoy ${ }^{1}$, D.V. Blyshchyk ${ }^{2}$, P.A. Feoktistov ${ }^{2}$
}

\author{
${ }^{1}$ Agrometeorology, Odessa State Environmental University, 15 Lvovskaya Street, Odessa, 65016, Ukraine. \\ ${ }^{2}$ Department of Resistance to Abiotic Factors, Odessa Plant Breeding and Genetics Institute-National Center of Seed and Cultivar \\ Investigation of the Ukrainian Academy of Agricultural Sciences, Ovidiopol'skaya road, Odessa, 65036, Ukraine. \\ E-mail: apolevoy@te.net.ua
}

\section{Received: 31.07.2019. Accepted: 30.08.2019}

\begin{abstract}
A dynamic model of the formation of winter hardiness of winter wheat plants during the autumn period of vegetation, which describes the growth processes, plant development and the passing of the two phases of the autumnal hardening under the effect of agrometeo-rological conditions in autumn, was developed. Effects of intensity of photosynthetically active radiation (PAR), sunlight levels, air temperature and soil moisture on the increment of reserves of photosynthesis products and soluble carbohydrates in winter wheat plants are described. The results of numerical experiments showed a significant influence of intensity of sunlight levels and air temperature on the passing of two phases of hardening during autumnal period of vegetation of winter wheat plants.
\end{abstract}

Keywords: Winter wheat; photosynthesis; respiration; carbohydrates; biomass; leaf area; hardening; formation of winter hardiness; mathematical model

\section{Introduction}

There is a steady increasing in demand for food products in a global scale that leads to the necessity to intensify the crop production. In conditions that exacerbates by global climate change, the usage of mathematical modeling can be an effective tool for solving issues of optimizing the system of land use. At the same time, the range and scale of the simulated processes is extremely huge: from global ecology to prognostication of the dynamics of individual components of agrocenoses.

In the system of interaction "organism-environment" the period of autumn vegetation of winter wheat plants is one of the most important preparatory stages in charge of the realization of their biological potential. The state of winter crops after finishing of the autumn vegetation is crucial for their overwintering. One of the main processes that predetermines the future harvest of winter wheat is hardening to unfavorable meteorological conditions of the winter period.

It is known that the basis of scientific ideas about the character of plant hardening is the theory of Tumanov, which was developed in the works of Vasilyeva, Vlasyuk, Protsenko, Fedorov, Kirichenko and other scientists Protsenko et al., (1969); Tumanov (1979); Fedorova (1972) Tumanov, in particular, figured out that the frost and winter hardiness of plants are largely determined by the conditions for their entry into winter dormancy. According to the Tumanov's theory of hardening, the preparation of winter wheat plants for overwintering runs in two stages Tumanov (1979).

The first stage of hardening begins in the second half of the autumn period, under conditions of good lighting, when air temperature decreases significantly at night time. The optimum air temperatures are $+6^{\circ} \mathrm{C}$ to $+10^{\circ} \mathrm{C}$ at daytime and $+2^{\circ} \mathrm{C}$ to $+3^{\circ} \mathrm{C}$ at night.

Long-term researches show that in the years when there is mainly cloudy weather with low light intensity during the hardening period, the winter wheat plants are hardened and characterized by a low level of frost resistance formation Netis (2011); Litvinenko et al., (2004). In such years, there is a small quantity of sugars $(20-28 \%)$ that accumulate in the tillering nodes of plants, while under normal hardening conditions the sum is $35-40 \%$ and even more.

Maksimov also pointed it out that the areas where there are many clear days in autumn, winter cereals enter into the winter more hardened than in regions where cloudy days pre- dominate. The best conditions for hardening is the presence of air temperatures up to $+10^{\circ} \mathrm{C}$ to $+15^{\circ} \mathrm{C}$ at the daytime, and when the air temperature is below $0^{\circ} \mathrm{C}$ not less than 15 days at night. According to Gassner and Grimm, the best plant hardening conditions are 10 days with an air temperature $+5^{\circ} \mathrm{C}$, and the 5 day with a temperature $-2^{\circ} \mathrm{C}$ Yakovlev (1966). Lichikaki specifies that the first stage of hardening of winter cereals occurs not only on clear days, but also under diffuse lighting Lichikaki (1974).

On sunny autumn days, photosynthesis processes can go relatively intensively during positive air temperatures. In the evening, at night and morning hours, when there is decreasing in air temperature, the excess of photosynthesis products, which is formed and not used for growth processes, goes on the formation and accumulation of carbohydrates in leaves and tillering nodes of winter wheat plants Antonenko (2002); Kovtun et al., (1990a); McMaster and Wilhelm (2003a).

After the ending of the first hardening stage, winter wheat plants withstand a decrease in soil temperature at the depth of the node tillering up to $-12^{\circ} \mathrm{C}$ Tumanov (1979) Polevoy (2013)

The air temperature transition through 0 downwards is taken as the ending of the first hardening stage period. Tumanov recommends hardening plants for 7-8 days Tumanov(1979). However, according to others scientists Netis (2011), the first stage of hardening lasts approximately 20 days.

According to Tumanov, the second stage of hardening passes at air temperatures $-2^{\circ} \mathrm{C}$ to $5^{\circ} \mathrm{C}$ and does not require the presence of light. According to Tumanov, the duration of the second stage is 3-5 days. Panchenko assumes that the second stage of plant hardening passes at temerature $-3^{\circ} \mathrm{C}$ within 8-12 days Panchenko (1960).

The processes of photosynthetic metabolism has a certain value during the passage of the second stage of hardening. This question is covered in the literature rather contradictory. 
According to Tumanov, during this period light does not affect on increasing of the level of plant frost resistance at negative air temperatures. Panchenko cites data according to which lighting during this period facilitates increasing in the sugar content in plant tissues and, therefore, the level of frost resistance Panchenko (1960). The results Kovtun et al., (1990b) confirm the positive effect of sunlight on the process of sugar accumulation in autumn at negative air temperatures. Interest in clarifying the role of sugars in the process of overwintering of winter plants is due to the fact that sugars are the main energy substance for the life processes, primarily for the respiration of wintering plants. The protective role of sugars is to increase the concentration of cell sap, to reduce the mass of intracellular ice and, thereby, protect the colloidal mass of the cytoplasm from coagulation when it is affected by low temperatures. A sharp increase in frost resistance in the second stage of hardening occurs only in plants that previously accumulated a sufficient reserve of sugars.

\section{Results}

Frost resistance of plants mainly develop during a stable transition of air temperature through $0^{\circ} \mathrm{C}$ and its further decreasing up to $-10^{\circ} \mathrm{C}$. Period of the second stage of hardening is determined by these conditions Lichikaki (1974). After passing the second stage of hardening, the critical freezing temperature at the depth of the winter wheat tillering node of medium resistant frost varieties decreases up to $-18^{\circ} \mathrm{C}$, and high-frostresistant varieties decreases up to $-20^{\circ} \mathrm{C}$ and lower Tumanov (1979); Polevoy (2013).

Despite of significant accomplishments in winter hardiness of winter wheat plants studies, only a small number of models are devoted to the influence of genetic and environmental factors on plant wintering Antonenko (2002); Bergjord et al., (2008a); Lecomte et al., (2003a); Ritchie et al. (1985a); Fowler et al., (1999a) Curry (1971a); Hunt and Pararajasingham (1995a); McMaster and Wilhelm (2003b) Over the past 20 years, it has been developed more than 70 models for winter wheat crops that simulate changes in crop productivity in response to environmental factors Ritchie et al., (1985a); Hunt and Pararajasingham (1995b); Porter and Semenov (2005); McMaster and Wilhelm (2003a) McMaster and Wilhelm (2003c) Nowadays, the most popular models that simulate the wintering period of winter wheat plants are FROSTOL model Bergjord et al., (2008b), a Canadian model developed by Fowler CERES-Wheat (1999) Fowler et al., (1999b) Ritchie et al., (1985b) and a model developed by Lecomte Lecomte et al., (2003b).

The mathematical description and modeling of the period of autumn vegetation and the formation of winter hardiness makes it possible to obtain data on bushiness, accumulation of sugars in winter wheat plants leaves and tillering nodes, water content of tissues and further prediction of plants overwintering.

The aim of the study is to consider approaches and methods for modeling of the formation of winter hardiness in winter wheat plants, a description of the developed model structure and the results of numerical experiments.

\section{Description of the model of winter hardiness formation of winter wheat plants}

The concept of modeling of winter hardiness formation by winter wheat plants is based on the concept of the presence of two hardening stages of winter crops under the influence of agrometeorological conditions of the autumn period. The first stage occurs under conditions of high level of sunlight, while the air temperature decreases significantly at night. The second stage takes place at air temperatures $-2^{\circ} \mathrm{C}$ to $5^{\circ} \mathrm{C}$.

Thus, the following physiological and biochemical processes caused by the genotype and occurring in the plant under the influence of agrometeorological conditions are modeled: processes of photosynthesis, respiration, growth and development of plants; formation of over ground and underground parts of plants; formation of tillering shoots; the formation of photosynthesis reserves and the accumulation of sugars in the over ground parts and tillering nodes; the amount of free and bound water in plant cells. The block diagram of the model is shown in figure 1.

Figure 1. The block diagram of the dynamic model of the winter hardiness formation by winter wheat plants during autumn-winter period.

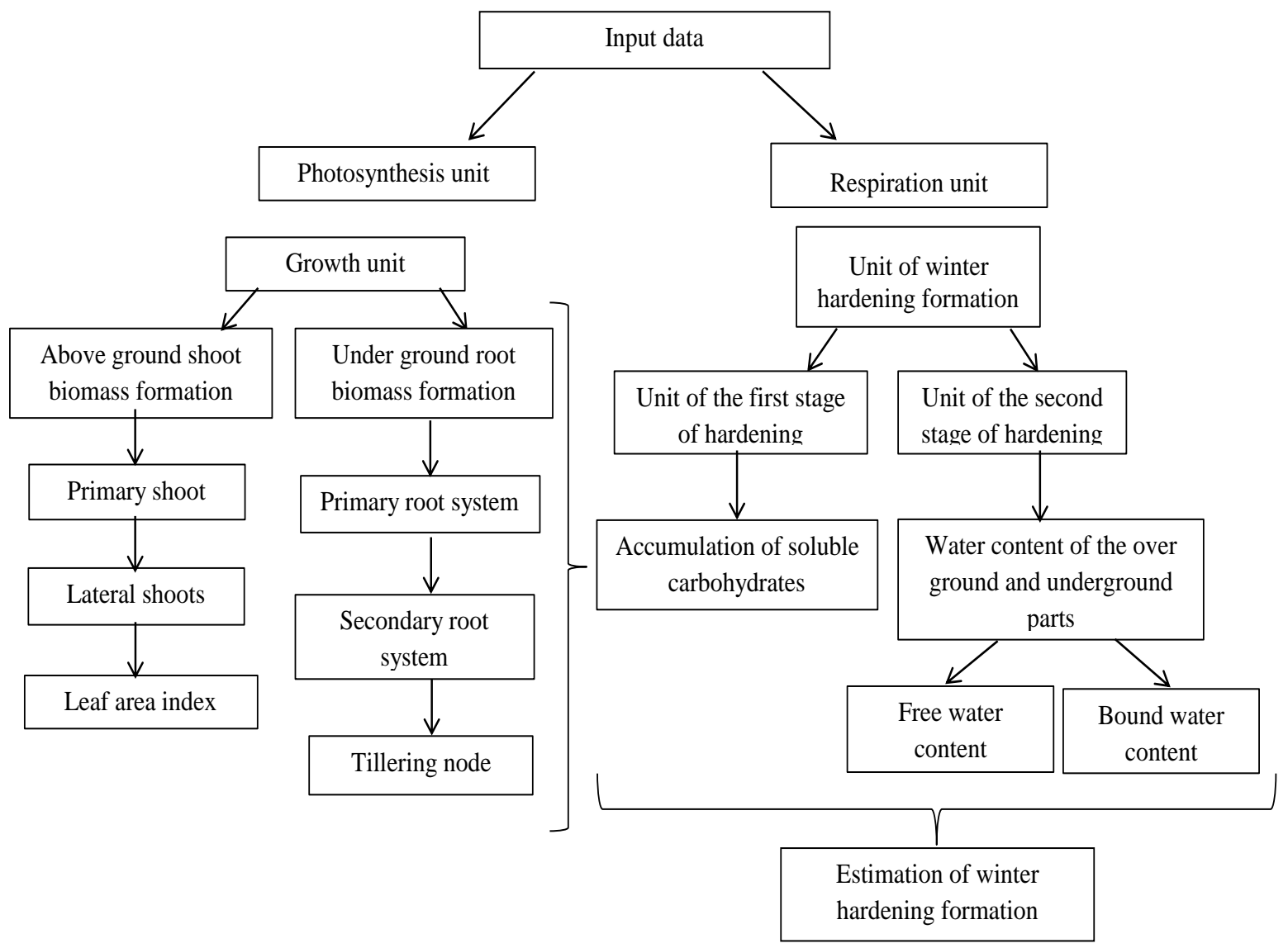


At the first stage, the model describes the processes of photosynthesis and respiration during the transitional stage of winter wheat plants to an independent autotrophic nutrition after germination. Next, the formation of the over ground and underground parts of plants is described. When the average daily air temperature passes over $+5^{\circ} \mathrm{C}$ downwards, the processes of soluble carbohydrates accumulation in the leaves and tillering nodes of winter wheat plants are described. At the transition of average daily air temperature through $0^{\circ} \mathrm{C}$, the content of bound and free water in plant cells is modelled. The hardening level is estimated by the amount of accumulated sugars in plant tillering nodes and leaves and the ratio of bound and free water. Primarily, simulation of winter wheat autumn vegetation includes a quantitative description of the processes of photosynthesis, respiration and growth.

Photosynthesis is the main process of formation of organic substances in plant cells. The process of photosynthesis is described by a semiempirical formula Bihele et al., (1980), in which, in addition to such environmental factors as photosynthetically active radiation (PAR) and $\mathrm{CO}_{2}$ concentration in the atmosphere, also takes into consideration the influence of the level of mineral nutrition, the phase of plant development, temperature regime and moisture supply of plants Polevoy (1988).

At the first stage, the model describes the processes of photosynthesis and respiration during the transitional stage of winter wheat plants to an independent autotrophic nutrition after germination. Next, the formation of the over ground and underground parts of plants is described. When the average daily air temperature passes over $+5^{\circ} \mathrm{C}$ downwards, the processes of soluble carbohydrates accumulation in the leaves and tillering nodes of winter wheat plants are described. At the transition of average daily air temperature through $0^{\circ} \mathrm{C}$, the content of bound and free water in plant cells is modelled. The hardening level is estimated by the amount of accumulated sugars in plant tillering nodes and leaves and the ratio of bound and free water. Primarily, simulation of winter wheat autumn vegetation includes a quantitative description of the processes of photosynthesis, respiration and growth.

Photosynthesis is the main process of formation of organic substances in plant cells. The process of photosynthesis is described by a semiempirical formula Bihele et al., (1980), in which, in addition to such environmental factors as photosynthetically active radiation (PAR) and $\mathrm{CO}_{2}$ concentration in the atmosphere, also takes into consideration the influence of the level of mineral nutrition, the phase of plant development, temperature regime and moisture supply of plants Polevoy (1988).

$\mathrm{P}=\frac{1}{1 / \mathrm{P}_{\mathrm{pot}} \mathrm{K}_{\mathrm{P}}\left(\mathrm{N}_{\mathrm{str}}^{\mathrm{L}}\right)+1 /\left(\mathrm{a}_{\mathrm{C}} \mathrm{C}_{0}\right)+1 /\left(\mathrm{a}_{\mathrm{P}} \mathrm{PAR}\right)} \min \left\{\mathrm{a}_{\mathrm{P}}, \psi_{\mathrm{P}}, \frac{\mathrm{ET}}{\mathrm{ET}_{\mathrm{pot}}}\right\}$

where $\mathrm{P}_{\text {pot }}$ the intensity of potential photosynthesis, $\mathrm{mg} \mathrm{CO} \mathrm{CO}_{2}{ }^{*} \mathrm{dm}^{-2} * \mathrm{~h}^{-1} ; \mathrm{a}_{\mathrm{C}}$ the photosynthesis 'light response curve', relative units; COconcentration of $\mathrm{CO}_{2}$ in the atmosphere; ap-slope of the photosynthesis 'light response curve', $\mathrm{mg} \mathrm{CO}_{2}{ }^{*} \mathrm{dm}^{-2} * \mathrm{~h}^{-1} /\left(\mathrm{W}^{*} \mathrm{~m}^{-2}\right)$; PAR absorbed PAR by vegetation, $\mathrm{W}^{*} \mathrm{~m}-2$; aP-ontogenetic curve of photosynthesis, relative units; P-temperature response of photosynthesis, relative units; $\mathrm{K}_{\mathrm{P}}\left(\mathrm{N}_{\mathrm{str}}^{\mathrm{L}}\right)$-mineral supply ratio of plants, relative units; ET-evapotranspiration, $\mathrm{mm}^{*} \mathrm{dm}^{-1}$; ETpot evaporation, $\mathrm{mm}^{*} \mathrm{dm}^{-1}$.

Part of the carbon that is assimilated during photosynthesis is spent on plant respiration, that includes respiration for growth and respiration for supporting structures that are modeled using the concept McCree (1970), taking into consideration changes in respiration intensity in ontogenesis Polevoy (2013) and under the influence of air temperature Curry (1971b):

$$
\frac{\mathrm{dR}}{\mathrm{dt}}=\mathrm{a}_{\mathrm{R}}\left[\mathrm{C}_{\mathrm{G}} \frac{\mathrm{dm}}{\mathrm{dt}}+\mathrm{C}_{\mathrm{m}} \mathrm{m} \varphi_{\mathrm{R}}\right]
$$

where $a_{R}$ is the ontogenetic curve of respiration; $C_{G}$ is a coefficient of expenditure on respiration for growth; $C_{m}$ is a coefficient of expenditure on maintenance respiration; $m$ is a mass of plants; ' $R$ is the temperature curve of respiration.

After the appearance of the first green leaf, the second and third embryonic leaves appear. The growth of the first and second pairs of germinal roots continues, coleoptile roots appear, i.e., the primary root system is formed under conditions of sufficient moisture. Simultaneously, a part of the stem of the former embryonic shoot transforms into the tillering node of the main (maternal) shoot. The phase of a sprout formation and tillering of the main shoot of winter wheat begins with the appearance of the first lateral shoot above the soil surface. The process of shoot formation and tillering occurs almost coextensive. Side shoots of the first order form shoots of the second one, and shoots of the second order form shoots of the $3^{\text {rd }}$, etc. The beginning of the tillering phase occurs when secondary (nodal) root develop from the tillering nodes first of the main, and then lateral shoots Orlyuk and Goncharova (2002).

A certain sum of effective air temperatures and total solar radiation is necessary for the appearance of each successive lateral tillering shoot. Therefore, the equation for the rate of formation of lateral tillers is next:

$$
\frac{\mathrm{dN}_{\mathrm{ts}}}{\mathrm{dt}}=\left\{\begin{array}{c}
\frac{2,3 \mathrm{~b}_{\mathrm{ts}}\left(10^{\mathrm{a}_{\mathrm{ts}}-\mathrm{b}_{\mathrm{ts}} / \mathrm{T}}\right) \times \mathrm{N}_{\mathrm{ts}}^{\max }}{\left(1+10^{\mathrm{a}_{\mathrm{ts}}-\mathrm{b}_{\mathrm{ts}} / \mathrm{T}}\right)^{2}} \min \left\{\mathrm{k}_{\mathrm{ts}}(\mathrm{Q}), \mathrm{k}_{\mathrm{ts}}\left(\sum \mathrm{T}_{\mathrm{ef}}\right)\right\}, \text { if } \mathrm{W}_{0-20}>\mathrm{W}_{0-20}^{\text {crit }} \\
0, \text { if } \mathrm{W}_{0-20} \leq \mathrm{W}_{0-20}^{\text {crit }} ; \sum \mathrm{T}_{\text {ef }} \leq \sum \mathrm{T}_{\mathrm{ef}}^{\mathrm{til}}
\end{array}\right.
$$

$\mathrm{dN}_{\mathrm{ts}} / \mathrm{dt}$-rate of lateral tillering shoots formation, $\mathrm{g} / \mathrm{m}^{2} *$ day; $\mathrm{Nts}^{\max }$ is a maximum possible number of tillering shoots under specified conditions, quantity/plant; $\mathrm{k}_{\mathrm{ts}}(\mathrm{Q}), \mathrm{k}_{\mathrm{ts}}\left(\Sigma \mathrm{T}_{\mathrm{ef}}\right)$ is a function of availability of required amount of solar radiation and warmth; $\mathrm{W}^{\text {crit }}$ is a critical moisture content in the arable soil layer at which tillering does not occur; $\mathrm{T}^{\text {til }}$ is a necessary sum of effective temperatures for the beginning of tillering process; $\mathrm{a}_{\mathrm{ts}}, \mathrm{b}_{\mathrm{ts}}$ are parameters.

The possible maximum amount of shoots under specified conditions, which will be provided by assimilates, is determined by the formula: 
$\mathrm{N}_{\mathrm{ts}}^{\max }=\frac{\mathrm{dm}_{\mathrm{ts}}^{\mathrm{res}} / \mathrm{dt}}{\mathrm{G}_{\mathrm{ts}}^{\max }}$

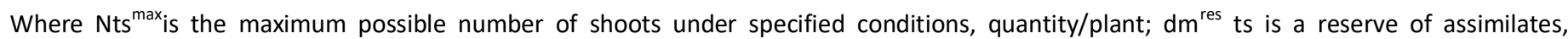
remaining after supplying the main shoot, $\mathrm{g} / \mathrm{m}^{2}$ day.

The reserve of assimilates is determined as the difference between the number of assimilates that moves to the over ground shoot system and the number of assimilates moves to the main shoot:

$\frac{\mathrm{dm}_{\mathrm{ts}}^{\text {res }}}{\mathrm{dt}}=\frac{\mathrm{dm}_{\text {ov.gr }}}{\mathrm{dt}}-\frac{\mathrm{dm}_{\text {main shoot }}}{\mathrm{dt}}$

where $\mathrm{dm}_{\text {overground }} ; \mathrm{dm}_{\text {main shoot }}$ is the biomass increment of the over ground shoot system and the main shoot, respectively, $\mathrm{g} / \mathrm{m} 2 *$ day; Gmaxtsis a maximum possible biomass increment of lateral shoots under specified conditions, that is defined as:

$\mathrm{G}_{\mathrm{ts}}^{\max }=\left(\mathrm{m}_{\mathrm{ts}} \times \mathrm{G}_{\mathrm{ts}}^{\mathrm{abs}}\right) \min \left\{\mathrm{k}_{\mathrm{ts}}\left(\mathrm{T}_{\mathrm{air}}\right), \mathrm{k}_{\mathrm{ts}}(\mathrm{W})\right\}$

where $m_{t s}$ is a biomass of lateral shoots, $\mathrm{g} / \mathrm{m}^{2 *}$ day; $\mathrm{G}_{\mathrm{ts}}^{\mathrm{abs}}$ is absolute relative biomass increment of lateral shoots, $\mathrm{g} / \mathrm{m}^{2} *$ day; $\mathrm{k}_{\mathrm{ts}}(T a i r), \mathrm{k}_{\mathrm{ts}}(\mathrm{W})$ are the functions of the influence of the air temperature and soil moisture on the growth of lateral shoots, respectively.

The dynamics of the biomass of the over ground shoot system and underground root system of winter wheat plants is described by equations Curry (1971b) Reynolds and Thornley (1982):

$$
\frac{\mathrm{dm}_{\text {overground }}}{\mathrm{dt}}=\left(\frac{\mathrm{dP}}{\mathrm{dt}}-\frac{\mathrm{dR}}{\mathrm{dt}}\right) \times \gamma_{\text {overground }}
$$

$\frac{\mathrm{dm}_{\text {ov.gr }}}{\mathrm{dt}}, \frac{\mathrm{dm}_{\text {und.gr }}}{\mathrm{dt}}$

Where $\frac{\mathrm{dm}_{\text {ov.gr }}}{\mathrm{dt}}, \frac{\mathrm{dm}_{\text {und.gr }}}{\mathrm{dt}}$ are the biomass increment of the over ground shoot system and underground root system, respectively, $\mathrm{g} / \mathrm{m}^{2} *$ day; Yov:gr is a growth function of the over ground shoot system of plants.

The increment in the over ground mass is distributed initially to the main shoot, then to lateral shoots of the 1st, 2nd and subsequent orders:

$\frac{\mathrm{dm}_{\text {mainshoot }}}{\mathrm{dt}}=\gamma_{\text {mainshoot }} \times \frac{\mathrm{dm}_{\text {ov.gr }}}{\mathrm{dt}}$

$\frac{\mathrm{dm}_{\mathrm{ls} 1}}{\mathrm{dt}}=\gamma_{\mathrm{lt} 1} \times\left(\frac{\mathrm{dm}_{\mathrm{ov} . \mathrm{gr}}}{\mathrm{dt}}-\frac{\mathrm{dm}_{\text {mainshoot }}}{\mathrm{dt}}\right)$

$\frac{\mathrm{dm}_{\mathrm{lsn}}}{\mathrm{dt}}=\gamma_{\mathrm{ltn}} \times\left(\frac{\mathrm{dm}_{\mathrm{ov} . \mathrm{gr}}}{\mathrm{dt}}-\frac{\mathrm{dm}_{\text {mainshoot }}}{\mathrm{dt}}-\sum_{\mathrm{i}}^{\mathrm{n}-1} \frac{\mathrm{dm}_{\mathrm{tsi}}}{\mathrm{dt}}\right)$

whered $\frac{\mathrm{dm}_{1 \mathrm{~s} 1}}{\mathrm{dt}}, \frac{\mathrm{dm}_{1 \mathrm{si}}}{\mathrm{dt}}, \frac{\mathrm{dm}_{1 \mathrm{sn}}}{\mathrm{dt}}$ is an increment of biomass of lateral shoots of the $1 \mathrm{st}, \mathrm{i}$-th, $\mathrm{n}$-th orders, g/m2*day; mainshoot, It1, Itnare distribution functions of assimilates for the main and lateral shoots.

The area of the assimilating surface is described by an equation:

$\mathrm{L}^{\mathrm{j}+1}=\mathrm{L}^{\mathrm{j}}+\frac{\Delta \mathrm{m}_{\mathrm{i}}^{\mathrm{j}}}{\sigma}$

where $L^{j+1}$ is the relative leaf area index, $\mathrm{m}^{2} / \mathrm{m}^{2}$; mji is an increment of the dry biomass of leaves, $\mathrm{g} / \mathrm{m}^{2} *$ day ; is a specific canopy leaf area density, $\mathrm{g} / \mathrm{m}^{2}$.

The flow of essential nutrients to the underground root system of plants goes to the formation of the primary, secondary root system and the tillering node: 
$\frac{\mathrm{dm}_{\mathrm{r} 1}}{\mathrm{dt}}=\gamma_{\mathrm{r} 1} \times \frac{\mathrm{dm}_{\text {und.gr }}}{\mathrm{dt}} \quad$ (13) $\frac{\mathrm{dm}_{\mathrm{r} 2}}{\mathrm{dt}}=\gamma_{\mathrm{r} 2} \times \frac{\mathrm{dm}_{\text {und.gr }}}{\mathrm{dt}}$

$\frac{\mathrm{dm}_{\mathrm{tn}}}{\mathrm{dt}}=\gamma_{\mathrm{tn}} \times \frac{\mathrm{dm}_{\text {und.gr }}}{\mathrm{dt}}$

where $\frac{\mathrm{dm}_{\mathrm{r} 1}}{\mathrm{dt}} ; \frac{\mathrm{dm}_{\mathrm{r} 2}}{\mathrm{dt}} ; \frac{\mathrm{dm}_{\mathrm{tn}}}{\mathrm{dt}}$ are the biomass increment of the primary, secondary root system and the tillering node, respectively, $\mathrm{g} / \mathrm{m} 2 *$ day; $r 1, r 2$, tn are growth functions of the primary, secondary root system and tillering node, respectively.

During the second half of autumn, decreasing in the average daily air temperature causes inhibition of growth processes. Because of lack of warmth, plants grow poorly, and the excess of photosynthetic products, that is not used for growth processes, leads to the formation of carbohydrates in the over ground shoot system and tillering nodes, which plays a protective role and ensuring the preparation of plants for wintering, i.e., the process of plant hardening.

The change in the mechanism of distribution of assimilates between the continued slow growth of plant organs and the formation of reserve of assimilates that is turning into sugars is simulated after a stable transition of air temperature through $+5^{\circ} \mathrm{C}$. The number of products of photosynthesis is compared with the maximum possible increment in the over ground shoot biomass and underground root biomass of plants, which are defined similarly to equation (6). The increment in the mass of the over ground shoot biomass and underground root biomass of plants is determined as:

$\frac{\mathrm{dm}_{\text {ov.gr }}}{\mathrm{dt}}=\left\{\begin{array}{c}\mathrm{G}_{\text {ov.gr }}^{\max }, \text { if } \frac{\mathrm{dP}}{\mathrm{dt}}>\mathrm{G}_{\text {ov.gr }}^{\max }+\mathrm{G}_{\text {und.gr }}^{\max } \\ \left(\frac{\mathrm{G}_{\text {ov.gr }}^{\max }}{\mathrm{G}_{\text {ov.gr }}^{\max }+\mathrm{G}_{\text {und.gr }}^{\max }} \times \frac{\mathrm{dP}}{\mathrm{dt}}-\frac{\mathrm{dR} \text { ov.gr }}{\mathrm{dt}}\right), \text { if } \frac{\mathrm{dP}}{\mathrm{dt}}<\mathrm{G}_{\text {ov.gr }}^{\max }+\mathrm{G}_{\text {und.gr }}^{\max }\end{array}\right.$

$\frac{\mathrm{dm}_{\text {und.gr }}}{\mathrm{dt}}=\left\{\begin{array}{c}\mathrm{G}_{\text {und.gr }}^{\max }, \text { if } \frac{\mathrm{dP}}{\mathrm{dt}}>\mathrm{G}_{\text {ov.gr }}^{\max }+\mathrm{G}_{\text {und.gr }}^{\max } \\ \left(\frac{\mathrm{G}_{\text {und.gr }}^{\max }}{\mathrm{G}_{\text {ov.gr }}^{\max }+\mathrm{G}_{\text {und.gr }}^{\max }} \times \frac{\mathrm{dP}}{\mathrm{dt}}-\frac{\mathrm{dR} \text { ov.gr }}{\mathrm{dt}}\right), \text { if } \frac{\mathrm{dP}}{\mathrm{dt}}<\mathrm{G}_{\text {ov.gr }}^{\max }+\mathrm{G}_{\text {und.gr }}^{\max }\end{array}\right.$

The excess of photosynthesis products is defined as the difference:

$\frac{\mathrm{dm}_{\text {res }}}{\mathrm{dt}}=\frac{\mathrm{dP}}{\mathrm{dt}}-\left(\mathrm{G}_{\text {ov.gr }}^{\max }+\mathrm{G}_{\text {und.gr }}^{\max }\right)$

where $\frac{\mathrm{dm}_{\text {res }}}{\mathrm{dt}}$ is the reserve of photosynthesis products, formed after meeting the needs of the underground and over ground parts of plants in assimilates, $\mathrm{g} / \mathrm{m}^{2} *$ day.

The concentration of the reserve products of photosynthesis is defined as the ratio:

$$
\mathrm{mc}_{\mathrm{res}}=\frac{\mathrm{m}_{\mathrm{res}}}{\mathrm{M}}
$$

where $\mathrm{mc}_{\text {res }}$ is the concentration of excess photosynthetic products in plants, $\mathrm{mg} / \mathrm{g}^{*}$ day; $\mathrm{M}$ is the mass of the plant, $\mathrm{g} / \mathrm{m}^{2} * \mathrm{day}$.

The process of formation of soluble carbohydrates in the over ground shoot system and tillering node is determined by the Michaelis-Menten kinetics equations type:

$$
\frac{\mathrm{dCS}_{\mathrm{ov} . \mathrm{gr}}}{\mathrm{dt}}=\frac{\frac{\mathrm{dCS}_{\mathrm{ov} . \mathrm{gr}}^{\mathrm{pot}}}{\mathrm{dt}} \times \mathrm{mc}_{\text {res }} \times \mathrm{K}_{\mathrm{ov} . \mathrm{gr}}^{\mathrm{M}-\mathrm{M}}}{\frac{\mathrm{dCS}_{\mathrm{ov} . \mathrm{gr}}^{\mathrm{pot}}}{\mathrm{dt}}+\left(\mathrm{mc}_{\mathrm{res}} \times \mathrm{K}_{\mathrm{ov} . \mathrm{gr}}^{\mathrm{M}-\mathrm{M}}\right)}
$$


$\frac{\mathrm{dCS}_{\mathrm{tn}}}{\mathrm{dt}}=\frac{\frac{\mathrm{dCS}_{\mathrm{tn}}^{\mathrm{pot}}}{\mathrm{dt}} \times \mathrm{mc}_{\mathrm{res}} \times \mathrm{K}_{\mathrm{tn}}^{\mathrm{M}-\mathrm{M}}}{\frac{\mathrm{dCS}_{\mathrm{tn}}^{\mathrm{pot}}}{\mathrm{dt}}+\left(\mathrm{mc}_{\mathrm{res}} \times \mathrm{K}_{\mathrm{tn}}^{\mathrm{M}-\mathrm{M}}\right)}$

Where $\frac{\mathrm{dCS}_{\mathrm{ov} . g r}}{\mathrm{dt}}, \frac{\mathrm{dCS}_{\mathrm{tn}}}{\mathrm{dt}}$ is the rate of formation of sugars in the over ground shoot system and $\frac{\mathrm{dCS}_{\mathrm{ov} . \mathrm{gr}}^{\mathrm{pot}}}{\mathrm{dt}}, \frac{\mathrm{dCS}_{\mathrm{tn}}^{\text {pot }}}{\mathrm{dt}}$ is the potential rate of sugars formation in the over ground shoot system and the tillering node, mg/day ; Kov:grMM ; KtnMM are Michaelis-Menten constants for the over ground shoot system and the tillering node, $\mathrm{mg} / \mathrm{g}$.

The amount of soluble sugars is determined separately for the over ground part of plants $\mathrm{SmCS}_{\mathrm{ov}: \mathrm{gr}}$ and tillering nodes $\mathrm{SmCS}_{\mathrm{tn}}$.

Plant tissue dehydration and the transition of free to bound water occur at the second hardening stage. Feature difference of free and bound water is determined by their different physiological value. The content of free water determines the intensity of physiological processes, and the content of the bound water determines the resistance of plants to unfavourable environmental conditions.

The increased content of free water in plant cells leads to an increase in the processes of growth, metabolism, and respiration, and thereby contributes to an increasing in the productivity of plants under optimal conditions of existence.

However, under unfavorable conditions, plants that have an increased content of bound water have an advantage that contributing to the preservation of a larger amount of nonfreezing water at temperatures below zero, which is one of the factors that increase cold resistance of plants Gusev (1974).

The water content of the underground part of plants is calculated as:

$\mathrm{W}_{\text {ov.gr }}=\left(89-0,038 \times \mathrm{k}_{\text {water }}\left(\sum \mathrm{T}_{\text {ef }}\right)+65\right) \times \mathrm{k}_{\text {water }}(\mathrm{W})$

wherek $_{\text {water }}(\Sigma T e f) ; k_{\text {water }}(W)$ are functions of the influence of warmth and moisture. The amount of bound water in the underground part of plants is determined by the formula:

$\mathrm{S}_{\mathrm{bw}_{\text {und.gr }}}=\mathrm{S}_{\mathrm{bw}_{\text {und.gr }}} \times \mathrm{k}_{\mathrm{bw}}\left(\mathrm{T}_{\text {air }}\right)$

where $k_{b w}\left(T_{\text {air }}\right)$ is the functions of the influence of air temperature.

The amount of free water in the underground part of plants is determined by the formula:

$\mathrm{S}_{\mathrm{fw}_{\text {und.gr }}}=\mathrm{W}_{\mathrm{fw}_{\text {und.gr }}}-\mathrm{S}_{\mathrm{bw}_{\text {und.gr }}}$

\section{Field and laboratory studies}

The objects of the study were 5 varieties of winter wheat like Odessa 16, Odessa 267, Antonovka, Albatross Odessa and Strumok, that were sown in the fields of the Odessa Plant Breeding and Genetics Institute-National Center of Seed and Cultivar Investigationon September 25 and October 2, 2013. The experiment was repeated three times, the area of the plot was $2 \mathrm{~m}^{2}$. Sowing was carried out with seeds treated with a Dunaevsky seed drill on the basis of a T-16 tractor.

In autumn plants were fed with N40P40K40 nitroammophobia Netis (2011). After the appearance of the first leaf, samples of 50 plants of each variety of winter wheat were selected once a day to determine the content of soluble sugars in the over ground part and tillering nodes of plants, the total water content of plant tissues, the presence of free and bound water.

The sugar content was determined by anthrone method Filippovich (1975). Determination of total water content and the presence of bound and free water were performed by the weight method Ermakov (1972). The article presents the averaged research results on five varieties of winter wheat of the first sowing period.

\section{Discussion}

Most of the initial parameters of the model were obtained in the course of laboratory and field experimental studies. Part of the parameters was obtained by analyzing the available literature data, as well as optimization and manual selection of the numerical values of the parameters. The model has a daily time step. Maximum, average and minimum air temperature, daily intake of solar radiation, reserves of productive moisture in the soil layer of $0-20 \mathrm{~cm}$ and the amount of precipitation are used as an input information in the model.

According to the Odessa Hydrometeorological Observatory at prevailing temperature conditions of 2013-2014, the termination of the autumn vegetation of winter wheat was observed on November 26, when the transition of average daily air temperature through $+5 \mathrm{C}$ was discovered. When the sowing date of winter wheat was on September 25, the sum of active air temperatures for the period of sowing - termination of the autumn growing season was $613^{\circ} \mathrm{C}$, and the duration of the period was 63 days.

One of the meteorological factors affecting on the dynamics of winter wheat plants is the amount of precipitation for the observed period. According to the experimental results, a significant increase in the dry biomass of the over ground parts of plants was observed on October 3-11 after precipitation, and increased by 1.5 times (from $0.15 \mathrm{~g}$ to $0.26 \mathrm{~g}$ per 10 plants). After raining, that was observed on November $20-28$, the value of the dry biomass of the over ground part of plants increased from 1.2 to $1.6 \mathrm{~g}$ per 10 plants respectively. Increasing in dry biomass became insignificant at the transition of average daily air temperature through $+5^{\circ} \mathrm{C}$ and the value of dry biomass of the above ground part of the plants was $2.5 \mathrm{~g}$ per 10 plants on December 25 (Figure 2). 
Figure 2. Predicted (1) and observed (2) simulation of the dynamics of over ground dry biomass and simulation predicted dynamics of underground dry biomass ( 3 ) of winter wheat plants parts, $(P<0.05)$.

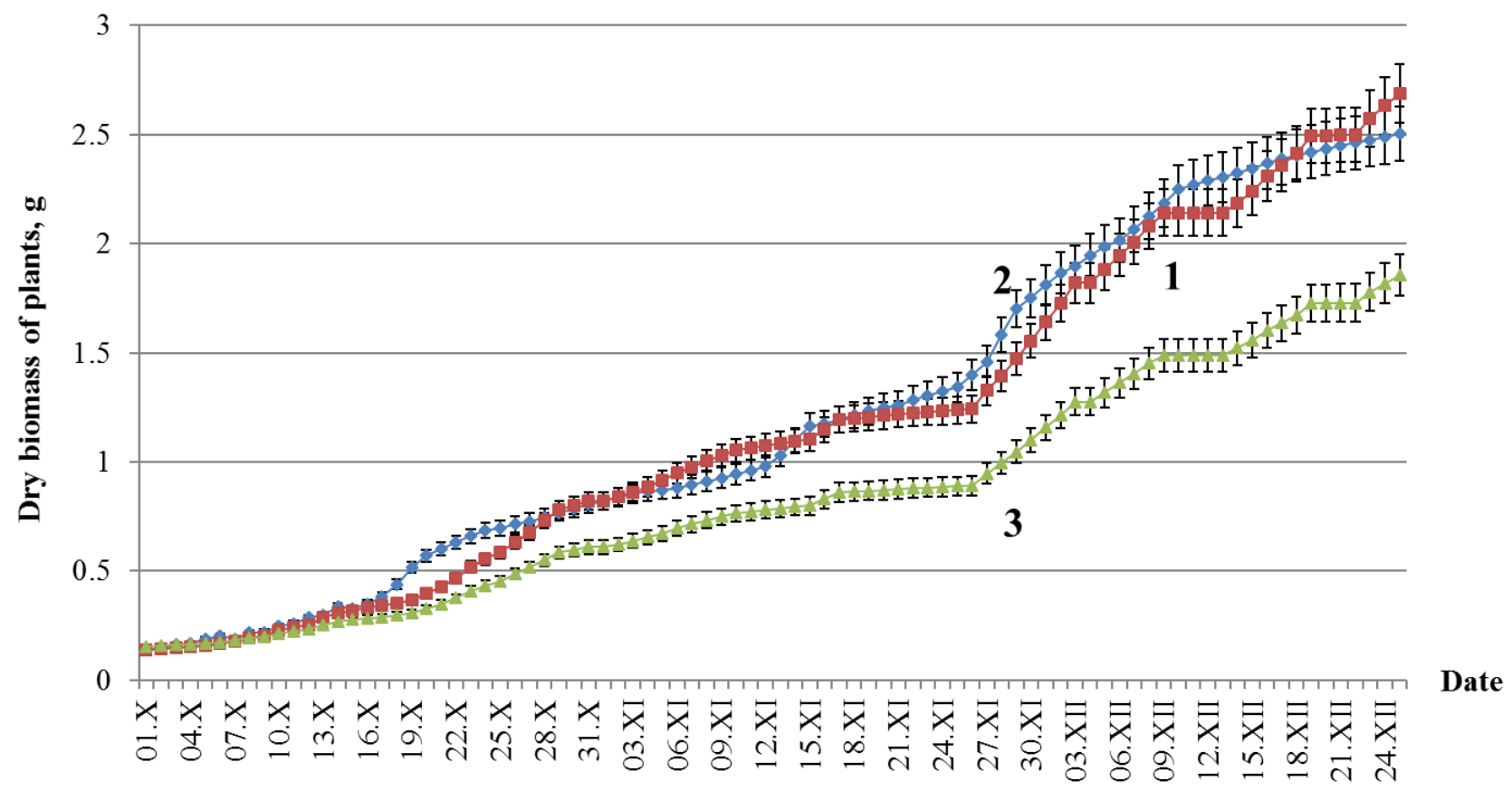

The value of dry biomass of the underground parts of plants of the first and second sowing dates was modelled that equal 1.8 and $1.5 \mathrm{~g}$ per 10 plants, respectively. According to our research, light intensity has a significant effect on sugar content in the over ground part and tillering nodes of winter wheat plants. For example, when the level of the total solar radiation was high, the content of soluble carbohydrates in the over ground parts of plants increased from 14 to $25 \%$ and from 8 to $10 \%$ respectively on 20-28 October and on $4-7$ November (Figure 3 ).

Figure 3. Predicted (1) and observed (2) simulation of the dynamics of soluble carbohydrate content in the over ground part of winter wheat plants, $(\mathrm{P}<0.05)$.

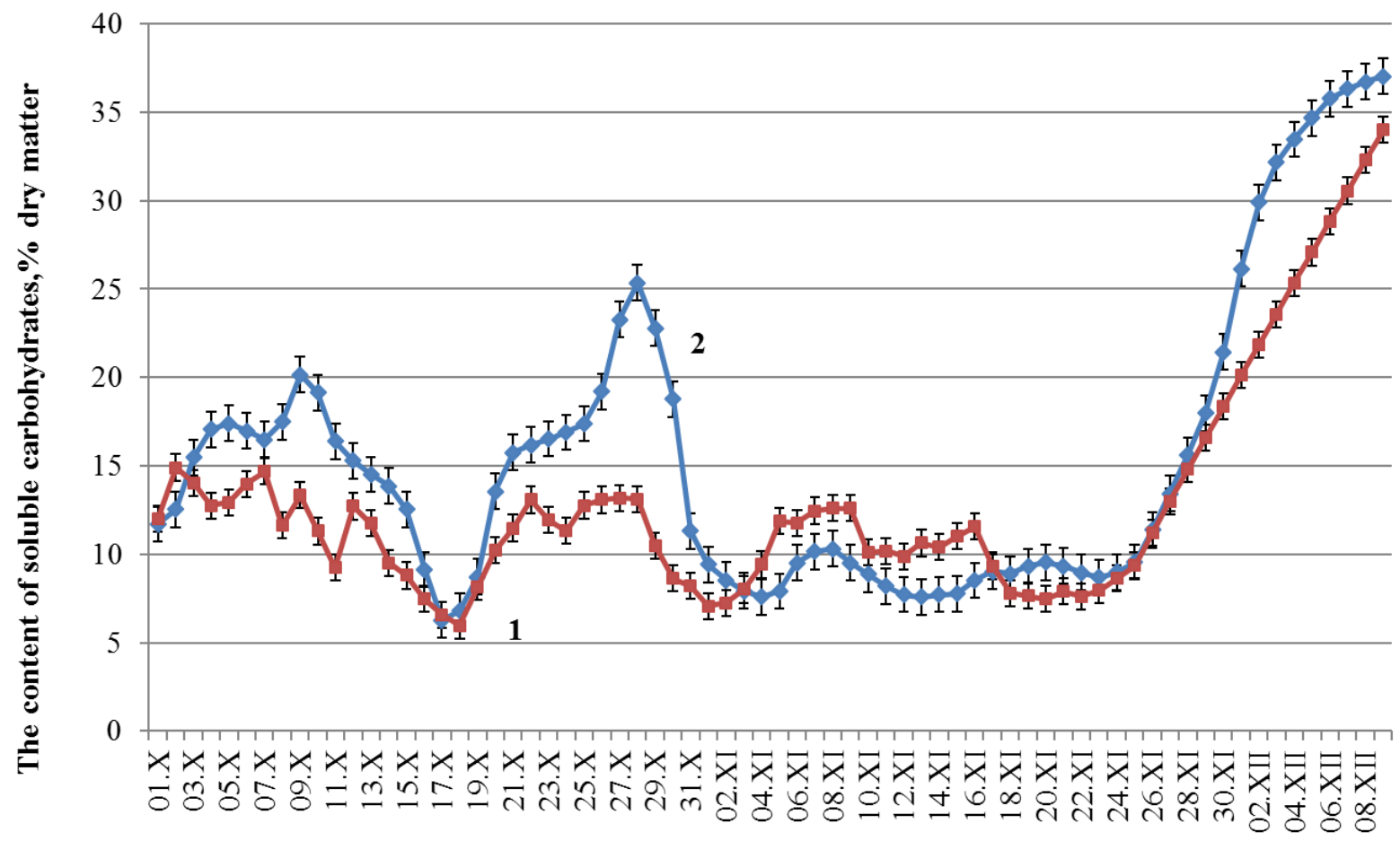

Date

In the presence of precipitation and overcast sky on 9-11 October, the sugar content in the over ground parts of plants decreased from 20 to 16 $\%$; the sugar content decreased from $16 \%$ on October 11 , and it was $6 \%$ on October 17 . The total content of soluble carbohydrates in tillering nodes of plants increased from 7 to $21 \%$ on October $19-21$ and from 17 to $25 \%$ on October $25-28$ when high light intensity was occurred (Figure 4). 
Figure 4. Predicted (1) and observed (2) simulation of the dynamics of the content of soluble carbohydrates in the tillering nodes of winter wheat plants, $(\mathrm{P}<0.05)$.

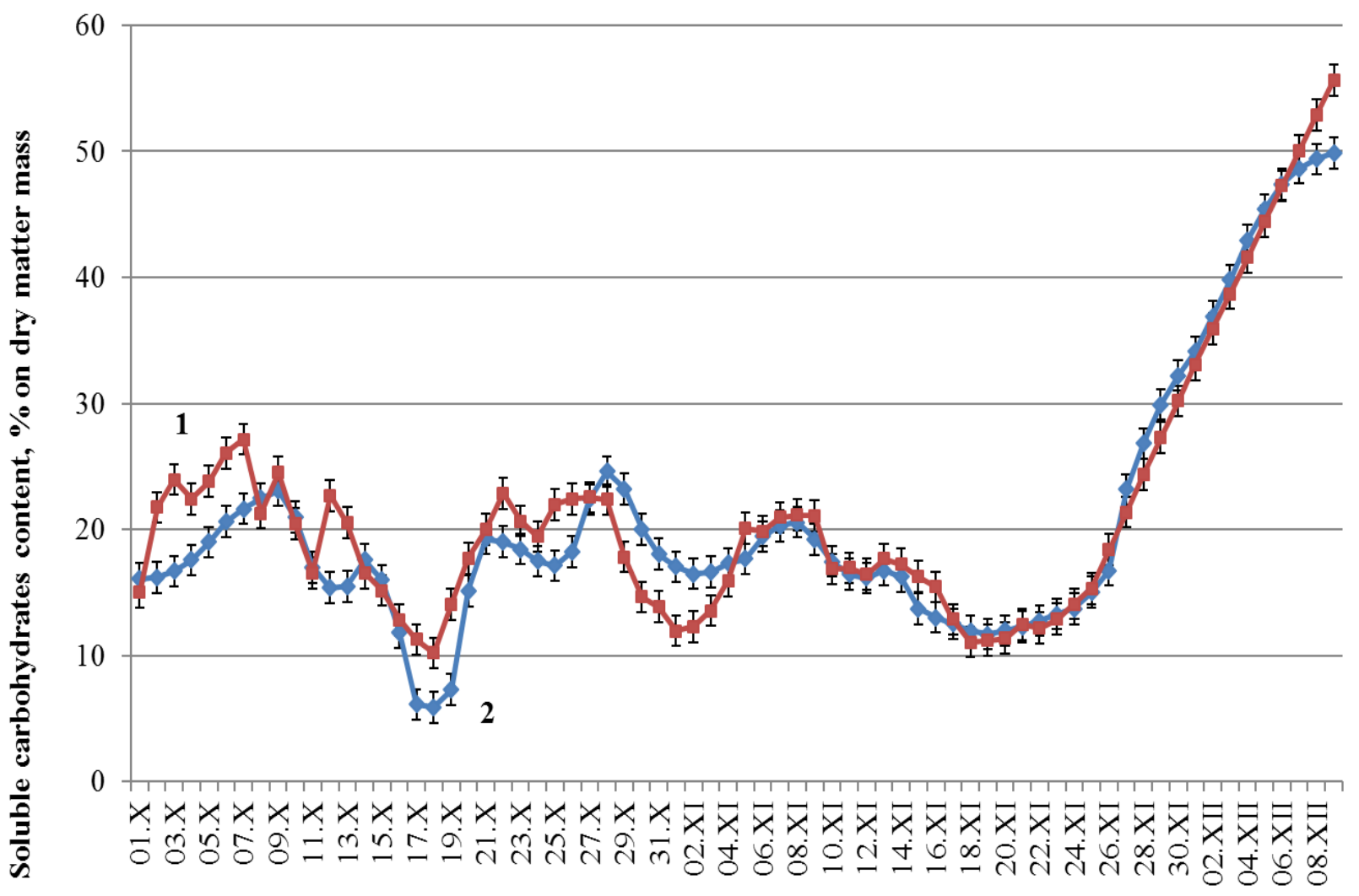

Date

In the year of research, the conditions for passing of the first hardening phase were favorable. When there is a transition of average daily air temperature through $+5^{\circ} \mathrm{C}$ in the direction of its reduction, there was a significant increase in sugar content in the over ground parts and tillering nodes of winter wheat plants.

According to our research, the content of soluble carbohydrates in the over ground parts of plants until the date of the termination of the autumn vegetation increased from 12 to $37 \%$ from dry weight, respectively. The content of soluble carbohydrates in tillering nodes plants by the date of the termination of the autumn vegetation increased from 15 to $50 \%$ from dry weight, respectively, which indicates a high level of hardening of plants.

A statistical analysis showed that there is a close negative correlation between the soluble carbohydrates content in the over ground parts of plants and the air temperature. The correlation coefficient is $r=-0.626$. There is a positive correlation between the soluble carbohydrates content in the over ground parts of plants and light levels. The correlation coefficient is $r=0,506$. There is a close negative correlation between the soluble carbohydrates content in the tillering nodes and temperature. The correlation coefficient is $r=-0.702$. There is a fairly close connection between the soluble carbohydrates content in the tillering nodes and the light level. The correlation coefficient is $r=0.496$. To test the adequacy of the model, the first experimental values were taken as initial values of the sugar content in the over ground part and tillering nodes of winter wheat plants in a field study. The initial model value of the sum of sugars is $12 \%$ of the mass of dry matter, and for tillering nodes is $16 \%$ of the dry weight.

Comparison of the values of the over ground part of the plant biomass with the actual data calculated using the model showed (Figure 2) a good agreement between the dynamics and absolute biomass values. The calculated value of the dynamics of the soluble carbohydrates content in the over ground parts of plants (Figure 3) and in tillering nodes also have a good agreement with field experiment data. The presence of a model that adequately describes winter hardiness formation made it possible to conduct a series of numerical experiments to assess the influence of agrometeorological conditions on the formation of photosynthesis products reserves, the increment of soluble carbohydrates in the first hardening stage and the dynamics of free and bound water in plant cells in the second hardening stage.

The greatest increase in reserves of photosynthesis products is observed at $P A R=0.9 \mathrm{cal} / \mathrm{cm} 2 * \min$ and air temperature $15^{\circ} \mathrm{C}$, the least increment is at PAR $=0.1 \mathrm{cal} / \mathrm{cm} 2^{*}$ min and air temperature $5^{\circ} \mathrm{C}$, while the increase in photosynthesis products reserves halved from 0.5 to 0.28 $\mathrm{mg} /$ day (Figure 5).

If the moisture reserves in the $0-20 \mathrm{~cm}$ layer are close to the minimummoisture holdingcapacity and an increase in the intensity of PAR up to 0.9 $\mathrm{cal} / \mathrm{cm} 2 \mathrm{~min}$, the increment in reserves of photosynthesis products increases to $0.5 \mathrm{mg}$ per day. The increment in reserves of photosynthesis products decreases threefold and equal $0.15 \mathrm{mg}$ per day if there is a gradual decrease in soil moisture up to 0.3 relative units from the minimum moisture holding capacity.

Further, in the course of a numerical experiment, the effect of the light intensity and air temperature on the growth dynamics of soluble carbohydrates in tillering nodes of winter wheat plants was considered. When the air temperature is above $5^{\circ} \mathrm{C}$ and in fair weather, there is the greatest increment in soluble carbohydrates from 3 to $5 \mathrm{mg}$ per day. When the weather is cloudy or overcast, the increment in soluble carbohydrates is significantly reduced (up to $2 \mathrm{mg}$ per day). 
Figure 5. The photosynthesis reserves of winter wheat plants increment response depending on the PAR intensity at different air temperatures.

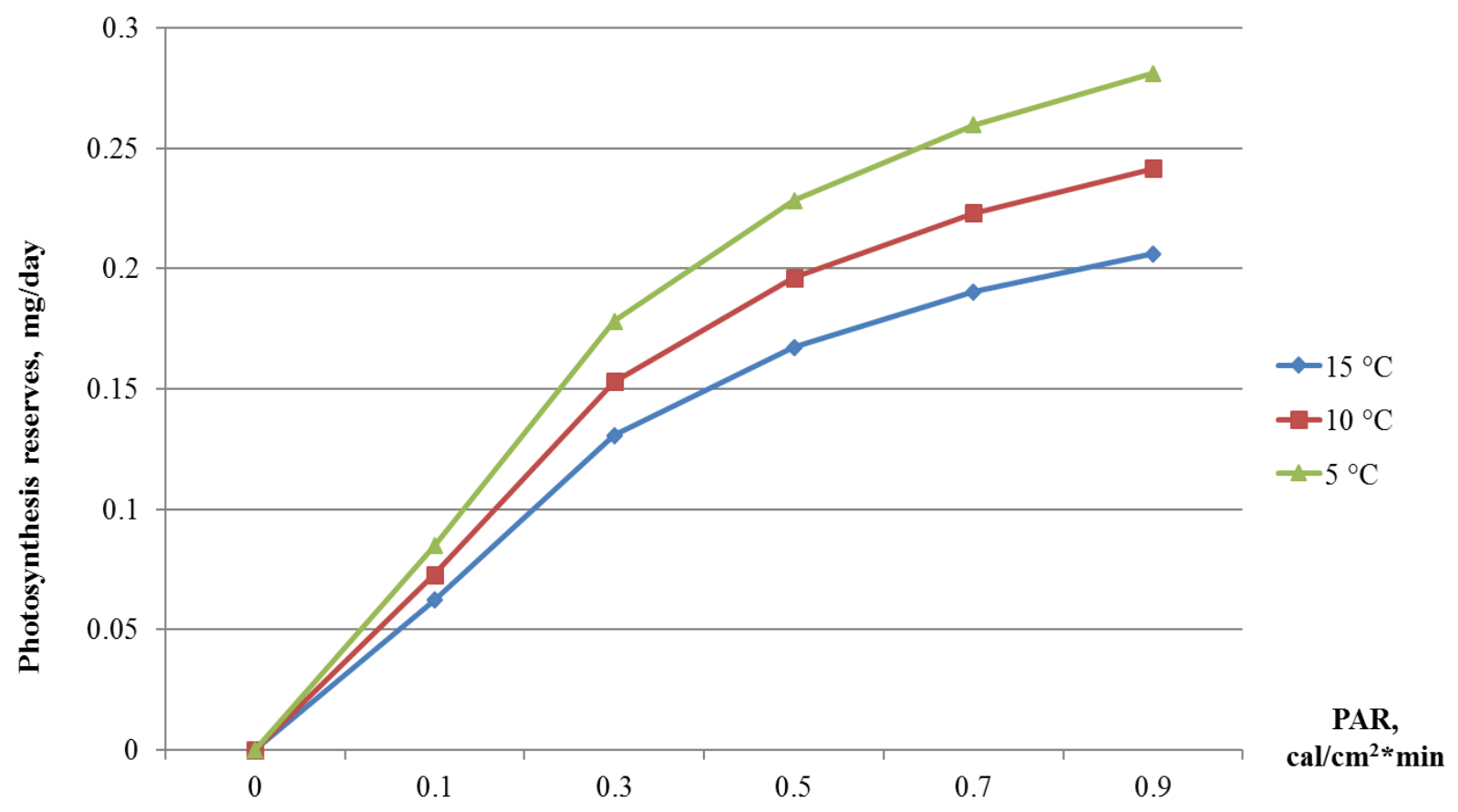

As previously mentioned, in the second half of autumn the course of air temperature decreasing, especially at night, leads to inhibition of growth processes, and those products of photosynthesis that are not used for increment of over ground and underground biomass go to the formation of soluble carbohydrates in plant tissues. With an increase in the amplitude of air temperature, an increase in the soluble carbohydrates in the plant tissues is observed. If at an air temperature amplitude of $3 \mathrm{C}$, the increase in soluble carbohydrates is $0.7-1.25 \mathrm{mg}$ per day, then with an increase in the amplitude of air temperature to $15^{\circ} \mathrm{C}$, the increase in carbohydrates increases to $3-5 \mathrm{mg}$ per day (Figure 6).

Figure 6. The soluble carbohydrates increment response to the concentration of photosynthesis reserves at different air temperatures ranges.

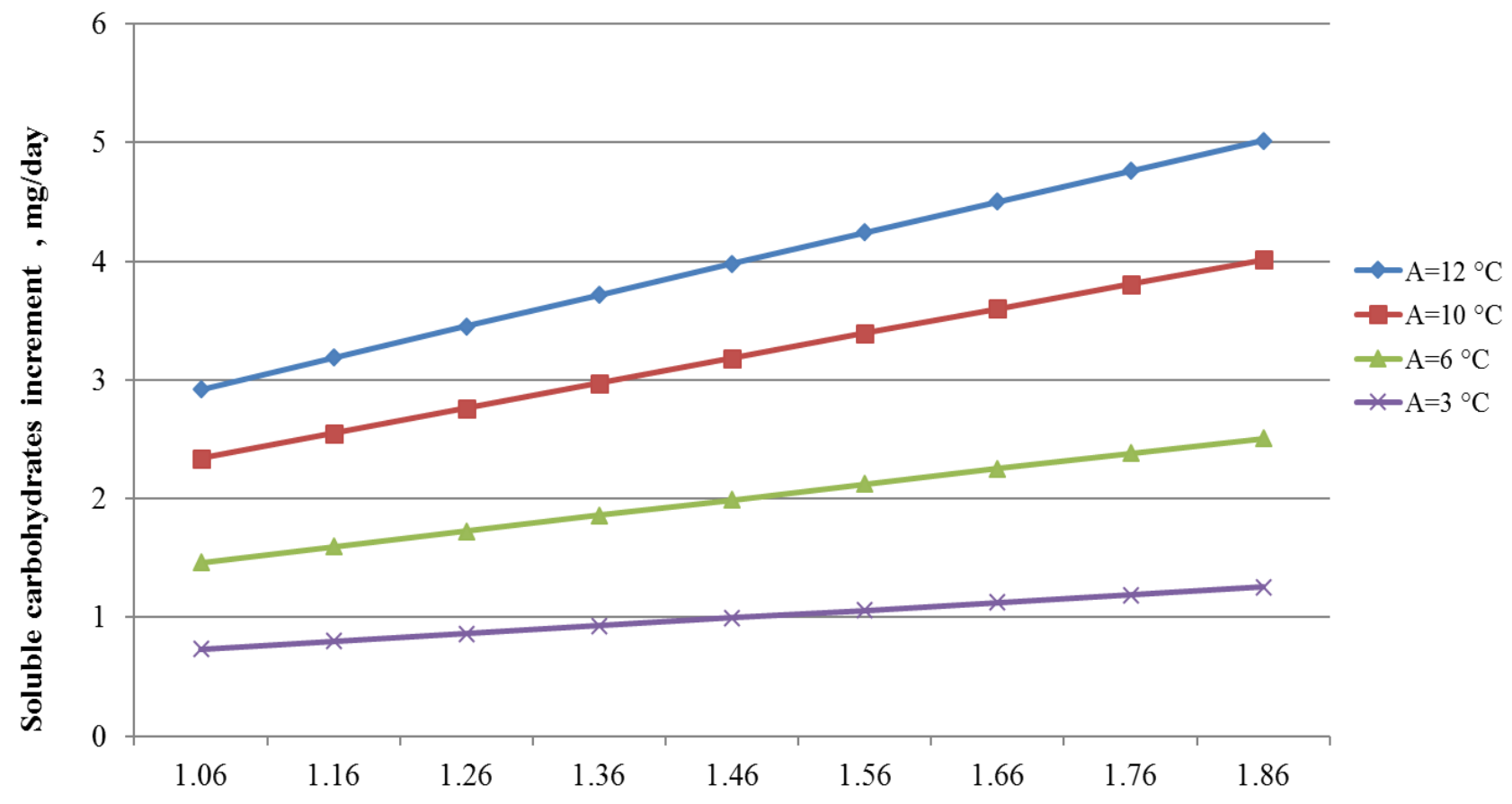

\section{Concentration of photosynthesis reserves, $\mathrm{mg} / \mathrm{g}$}

Under an increase in the duration of the period of the first hardening stage up to 20 days, the increase in soluble carbohydrates increases to 59 $\%$ by dry weight. Under reducing the duration of the period of the first hardening stage up to 10 days, the increase in soluble carbohydrates is reduced and is equal to $44 \%$ by dry weight (Figure 7). 
Figure 7. Dynamics of soluble carbohydrates accumulation depending on the duration of the first stage of plant hardening.

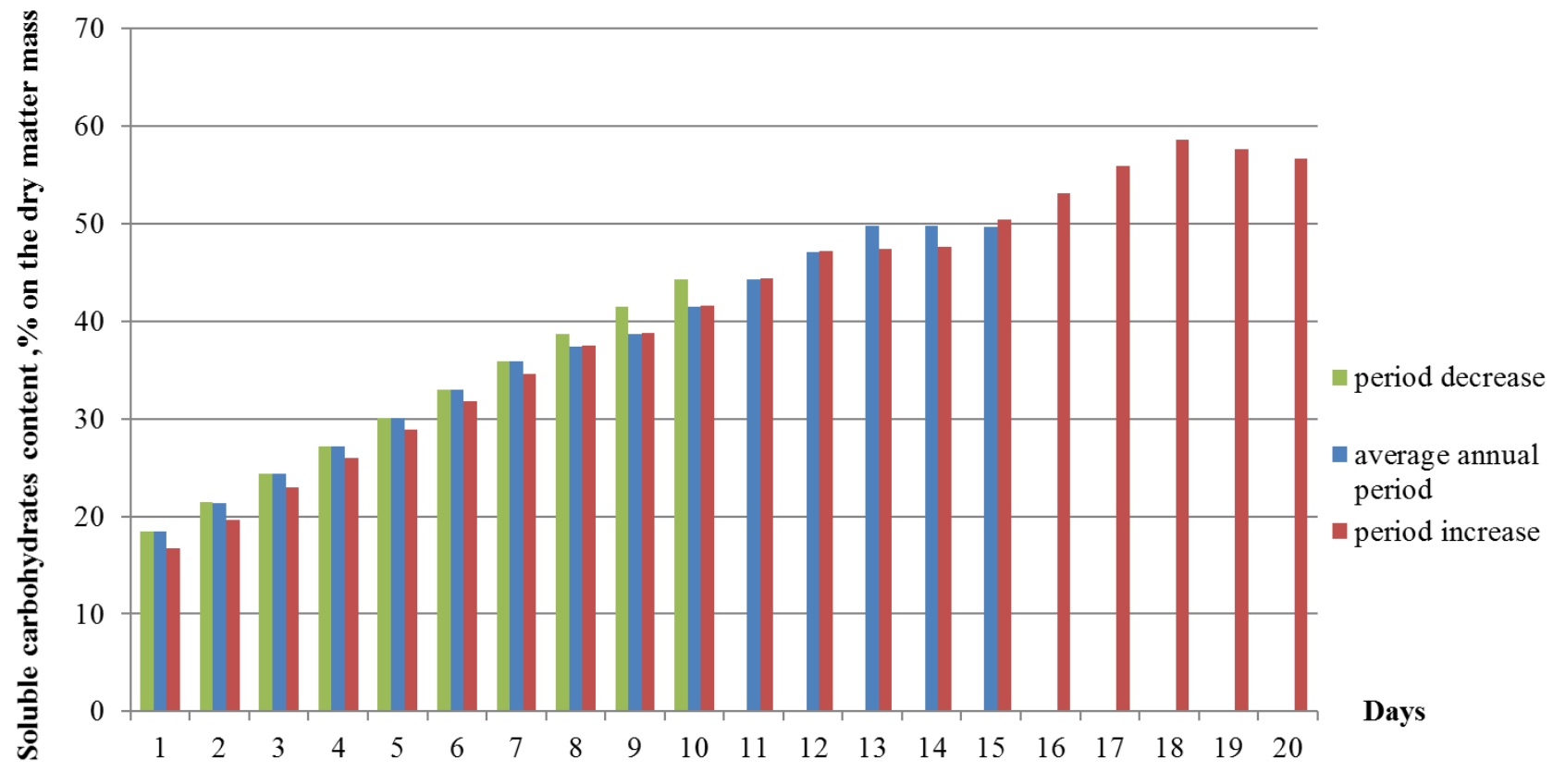

During the second hardening stage, there is a close connection between the amount of bound and free water in plant cells and the air temperature below $0^{\circ} \mathrm{C}$ (Figure 8). At a temperature $0^{\circ} \mathrm{C}$, the ratio of bound to free water is 0.095 , and at a temperature $-10 \mathrm{C}$, the ratio increases up to 0.29 . Thus, when there is a decrease in air temperature, the fractional composition of water changes due to the partial transition of free water into bound water, which significantly increases the winter hardiness of plants.

Figure 8. Dynamics of the content of free (1) and bound (2) water in plant tissues at air temperatures below $0^{\circ} \mathrm{C}$.

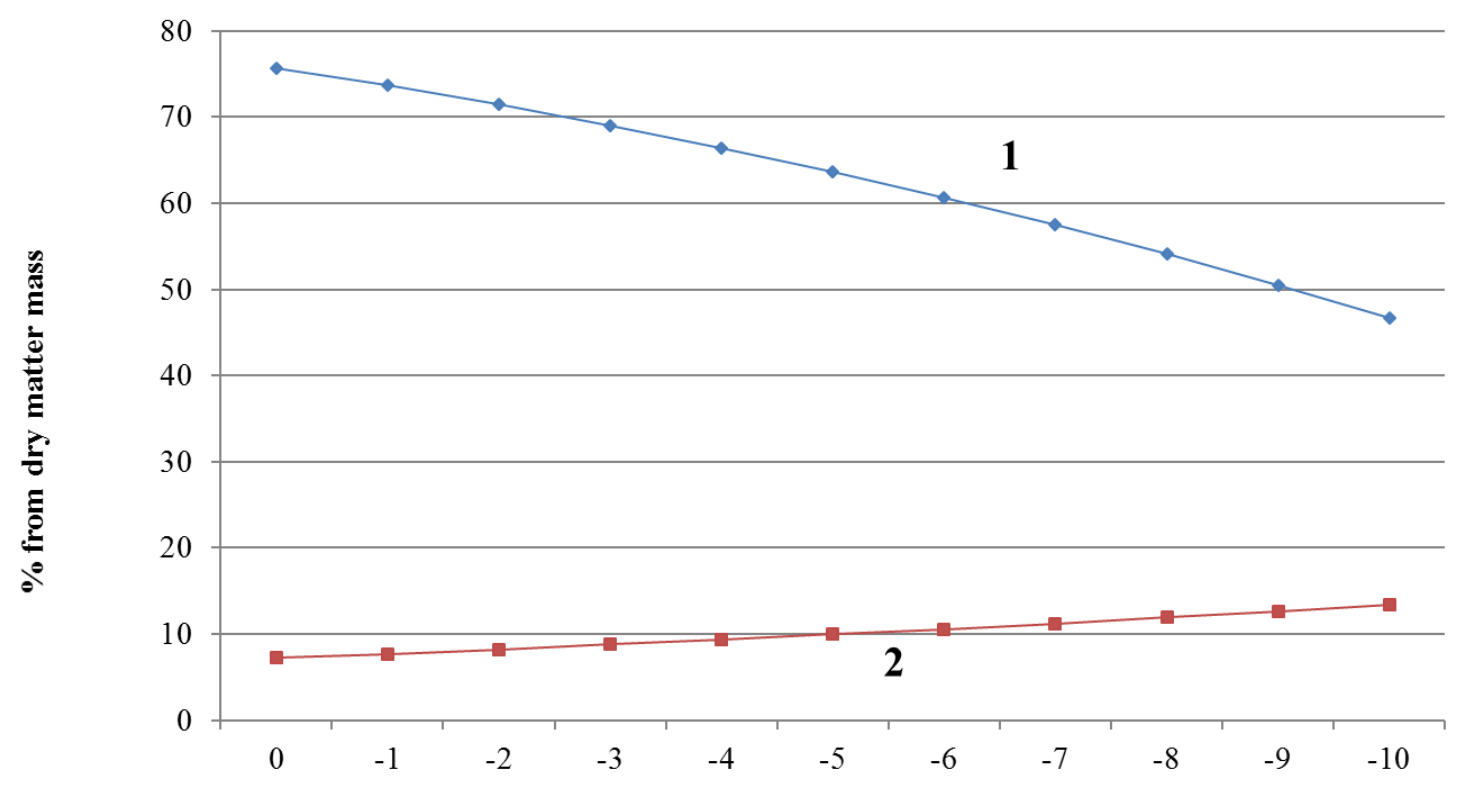

Air temperature, ${ }^{0} \mathrm{C}$

\section{Conclusion}

A dynamic model of the winter hardiness formation of winter wheat plants has been developed. The model describes the processes of growth and development of plants, as well as the passage of two stages of autumn hardening under the influence of agrometeorological conditions of 
autumn growing season. The estimation of the model adequacy showed that the average failure in the calculation of the model values of the dynamics of dry biomass accumulation of the over ground part of plants is $8 \%$. The average failure in the calculation of the model values of the sugar accumulation in the over ground parts and tillering nodes of plants is 22 and $15 \%$, respectively. There is a dependence of the increase in photosynthesis products reserves from the light intensity and air temperature: the maximum increase is observed when a combination of high light intensity $\left(0.9 \mathrm{cal} / \mathrm{cm}^{*} \mathrm{~min}\right)$ and air temperature $+15^{\circ} \mathrm{C}$ is observed. The maximum increase in soluble carbohydrates is observed at a high level of light intensity and a high value of the amplitude of air temperature $\left(A=10-12^{\circ} \mathrm{C}\right)$. During the plants hardening period, when the air temperature passes through $0^{\circ} \mathrm{C}$ towards negative temperatures, the ratio of bound water to free water increases due to the transferring of free water to bound water. Practical implement of the developed dynamic model of winter hardiness formation by winter wheat plants will facilitate decision-making process on the application of agrotechnical measures for growing winter wheat plants and optimizing the structure of sown areas of winter wheat varieties, which aimed at obtaining high and stable yields.

\section{References}

Antonenko, V. S. (2002). Dynamic modeling of growth, development and formation of productivity of winter wheat, ArtEk, Kyev. Bergjord, A. K., Bonesmo, H., Skjelvag, A. O. (2008a). Modelling the course of frost tolerance in winter wheat I. Model development. European Journal of Agronomy, 28, 321-330.

Bergjord, A. K., Bonesmo, H., Skjelvag, A. O. (2008b). Modelling the course of frost tolerance in winter wheat I. Model development. European Journal of Agronomy, 28, 321-330.

Bihele, Z. N., Moldau, H. A., Ross, Y. K. (1980). Mathematical modeling of transpiration and

Curry, R. B. (1971a). Dynamic simulation of plant growth, I. development of a model. ASAE Trans,14(5), 946-959.

Curry, R. B. (1971b). Dynamic simulation of plant growth, I. development of a model. ASAE Trans, 14(5), 946-959.

Ermakov, A. I. (1972). Methods of biochemical studies of plants, second ed.

Fedorova, N. A. (1972). Winter hardiness and yield of winter wheat.

Filippovich, Y. (1975). Workshop on General Biochemistry: Textbook manual for chemistry department students of pedagogical institutes. Fowler, D. B., Limin, A. E., Ritchie, J. T. (1999a). Low-temperature tolerance in cereals: model and genetic interpretation. Crop Science, 39, 626633.

Fowler, D. B., Limin, A. E., Ritchie, J. T. (1999b). Low-temperature tolerance in cereals: model and genetic interpretation. Crop Science, $39,626$. Gusev, N. A. (1974) Water condition in the plant.

Hunt, L. A., Pararajasingham, S. (1995a). CROPSIM-WHEAT: A model describing the growth and development of wheat. Can. J. Plant, 75, 619632.

Hunt, L. A., Pararajasingham, S. (1995b). CROPSIM-WHEAT: A model describing the growth and development of wheat. Can. J. Plant 75, 619-

632.

Kovtun, I. I., Goysa, N. I., Mitrofanov, B. A. (1990a). Optimization of conditions for the cultivation of winter wheat by intensive technology. Kovtun, I. I., Goysa, N. I., Mitrofanov, B. A. (1990b). Optimization of conditions for the cultivation of winter wheat by intensive technology. Lecomte, C., Giraud, A., Aubert, V. (2003a). Testing a predicting model for frost resistance of winter wheats under natural conditions. Agronomie, 23, 51-66.

Lecomte, C., Giraud, A., Aubert, V. (2003b). Testing a predicting model for frost resistance of winter wheats under natural conditions. Agronomie, 23, 51-66.

Lichikaki, V.N. (1974). Overwintering of winter crops.

Litvinenko, M. A., Lifenko, S. P., Druzyak, V. V., Druzyak, V. G. (2004). Influence of sowing dates and sublethal winter temperatures on survival and yield of winter wheat. J. Agric. Sci, 5, 27-31.

McCree, K. J. (1970). An equation for the rate of respiration of white clover plants growth under controlled 430

condition, in: Prediction and measurement of photosynthetic productivity.

McMaster, G. S., Wilhelm, W. W. (2003a). Phenological responses of wheat and barley to water and temperature: Improving simulation models. J. Agric. Science, 141, 129-147.

McMaster, G. S., Wilhelm, W. W. (2003b). Phenological responses of wheat and barley to water and temperature: Improving simulation models. J. Agric. Science, 141, 129-147.

McMaster, G. S., Wilhelm, W. W. (2003c). Phenological responses of wheat and barley to water and temperature: Improving simulation models. J. Agric. Science, 141, 129-147.

Netis, I. T. (2011). Winter wheat in the Southern. Monograph, Oldiplus, Kherson, Ukraine.

Orlyuk, A. P., Goncharova, K. V. (2002). Adaptive and productive wheat potentials.

Panchenko, N. P. (1960). Researches on the theory of hardening and their importance in boosting the winter hardiness of grain crops. Moscow. Polevoy, A. N. (1988). Applied modeling and predicting the productivity of crops.

Polevoy, A. N. (2013). Agricultural Meteorology.

Porter, J. R., Semenov, M. A. (2005). Crop responses to climatic variation. Philos Trans.

Protsenko, D. F., Vlasyuk, P. A., Kolosha, O. I. (1969). Winter hardiness of grain crops.

Reynolds, J. F., Thornley, J. H. M. (1982). A shoot: root partitioning model. Ann. Bot, 49, 585-597.

Ritchie, J. T., Godwin, D. C. (1985a). CERES Wheat. A simulation model of wheat growth and development college station. A\&M University Press, Texas.

Ritchie, J. T., Godwin, D. C. (1985b). CERES Wheat. A simulation model of wheat growth and development college station. A\&M University Press, Texas.

Tumanov, I. I. (1979). Physiology of hardening and frost resistance of plants.

Yakovlev, N. N. (1966). Climate and winter hardiness of winter wheat.

Citation: Polevoy, A.N., Blyshchyk, D.V., Feoktistov, P.A. (2019). Modeling of Winter Hardiness Formation in Winter Wheat Plants. Ukrainian Journal of Ecology, $9(3), 61-70$. 